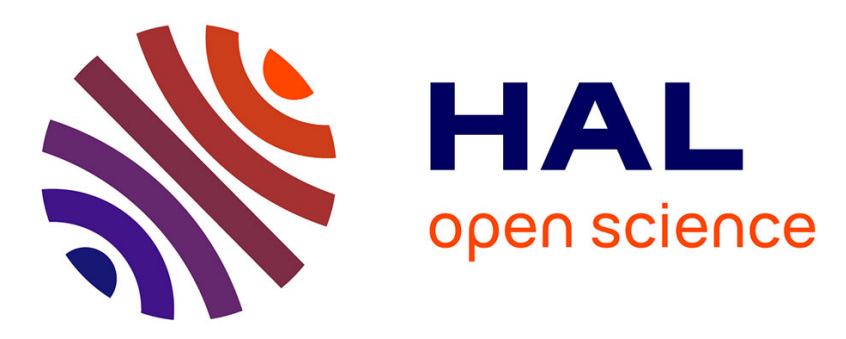

\title{
Yttrium segregation and intergranular defects in alumina
}

Daniele Bouchet, Sylvie Lartigue-Korinek, Régine Molins, Jany Thibault

\section{To cite this version:}

Daniele Bouchet, Sylvie Lartigue-Korinek, Régine Molins, Jany Thibault. Yttrium segregation and intergranular defects in alumina. Philosophical Magazine, 2006, 86 (10), pp.1401-1413. 10.1080/14786430500313804. hal-00513606

\section{HAL Id: hal-00513606 https://hal.science/hal-00513606}

Submitted on 1 Sep 2010

HAL is a multi-disciplinary open access archive for the deposit and dissemination of scientific research documents, whether they are published or not. The documents may come from teaching and research institutions in France or abroad, or from public or private research centers.
L'archive ouverte pluridisciplinaire HAL, est destinée au dépôt et à la diffusion de documents scientifiques de niveau recherche, publiés ou non, émanant des établissements d'enseignement et de recherche français ou étrangers, des laboratoires publics ou privés. 


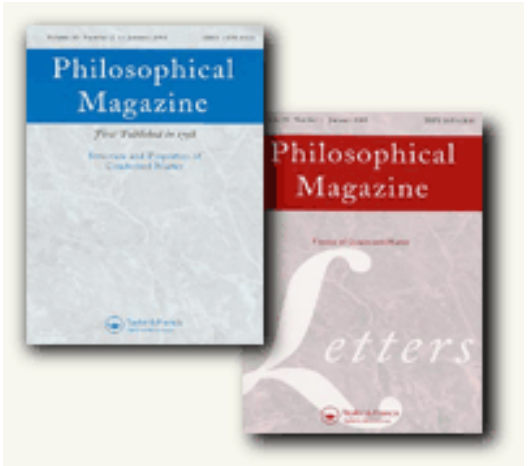

Yttrium segregation and intergranular defects in alumina

\begin{tabular}{|c|c|}
\hline Journal: & Philosophical Magazine \& Philosophical Magazine Letters \\
\hline Manuscript ID: & TPHM-05-Apr-0129.R1 \\
\hline Journal Selection: & Philosophical Magazine \\
\hline $\begin{array}{r}\text { Date Submitted by the } \\
\text { Author: }\end{array}$ & 18-Aug-2005 \\
\hline Complete List of Authors: & $\begin{array}{l}\text { Bouchet, Daniele; Université Paris-Sud, Physique des Solides } \\
\text { Lartigue-Korinek, Sylvie; CECM-CNRS } \\
\text { Molins, Régine; Ecole des Mines } \\
\text { Thibault, Jany; Université Aix-Marseille III, TECSEN-CNRS }\end{array}$ \\
\hline Keywords: & TEM, radiation damage, EELS, dislocations, alumina \\
\hline Keywords (user supplied): & intergranular segregation, yttrium \\
\hline
\end{tabular}

\section{今 scholaroNE" \\ Manuscript Central}




\title{
Yttrium segregation and intergranular defects in alumina
}

by

Danièle Bouchet*1 ${ }^{1}$, Sylvie Lartigue-Korinek**, Régine Molins*** and Jany Thibault****

* Laboratoire de Physique des Solides UA CNRS 8502 , Bât 510, Université Paris-Sud, 91405

- Orsay-France

** CECM-CNRS, UPR 2801, 94000 Vitry sur Seine - France

*** Centre des Matériaux, Ecole des Mines, BP 87, 91003 - Evry - France

**** Laboratoire TECSEN, UMR 6122 CNRS, Case 262 - Université Aix-Marseille III, Paul

Cézanne - Faculté des Sciences et Techniques de St Jérôme - 13397 Marseille - France

\begin{abstract}
:
Intergranular segregation of yttrium is investigated in a rhombohedral twin grain boundary of alumina. The deviation from the twin orientation is compensated by a periodic arrangement of intergranular dislocations. TEM tools (CTEM and HREM, EDXS, EFTEM and EELS/ELNES) have been used to characterize changes in chemical and electronic environments along this twin. Within the experimental limits, no $\mathrm{Y}$ is detected in the perfect twin parts. On the other hand, Y segregation occurs very locally in the dislocation cores on about four atomic planes perpendicularly to the GB which in fact corresponds to the step height associated with the interfacial dislocations. By comparison with an undoped bicrystal, both the dislocation distribution and the $\mathrm{Y}$ segregation localisation confirm the influence of $\mathrm{Y}$ on the dislocation mobility. Furthermore, in the Y-rich defects, high spatial resolution analysis of the energy loss near edge structures (ELNES) of the Al- $\mathrm{L}_{23}$ absorption edge brings some enlightenments about the $\mathrm{Al}^{3+}$ cation environment, provided the effects of local radiation damage are fully considered and under control.
\end{abstract} Deleted: II

\footnotetext{
${ }^{1}$ Corresponding author: bouchet@lps.u-psud.fr
} 


\section{I - Introduction}

The utmost importance of grain boundaries and intergranular segregations in the various macroscopic properties of polycrystalline materials is undoubtedly recognised but not fully understood from the origin point of view. The effect of segregation, whatever the property, is mainly conditioned by the induced changes of bonding in the structural units of the grain boundaries. Nevertheless, up until now, very few papers have been devoted to the electronic and atomic characterisation of intergranular dislocations (Z. Zhang et al. 2002).

Our study is motivated by the predominant role of yttrium on several properties of alumina. In particular, the creep rate is strongly reduced with Y doping (Cho et al. 1997, Lartigue-Korinek et al. 2002). The rather low solubility limit of Y in bulk alumina (Cawley and Halloran 1986) leads to segregation of this element in the GBs (Gruffel and Carry 1993, Gülgün, Putlayev and Rühle 1999, Wang et al. 2000). This large sized cation $\mathrm{Y}^{3+}$ is substituted to $\mathrm{Al}$ cation and induces local distortion of the oxygen ion lattice (Loudjani and Cortes 1994). Besides, the Y_segregation decreases the GB diffusivity and thus impedes the intergranular dislocation climb motion. In polycrystals, the intergranular Y content has been found to depend on the orientation of the GB plane (Bouchet et al. 1993).

With this in mind, the purpose of the present work is to deepen our knowledge of the atomic and chemical arrangement of an yttria-doped $\alpha$-alumina bicrystal. Up until now, the structure of the rhombohedral undoped-twin boundary, either fabricated by diffusion bonding procedure or issued from mechanical twinning, has been widely investigated by HRTEM (Geipel et al. 1994, Chen et al. 1995, Lartigue-Korinek and Hagège 1998, Nufer et al. 2001, Nishimura et al. 2003). It is described by a dense common (01 $\overline{1} 2)$ plane, and a common [0 $\overline{1} 11]$ direction in the GB plane which is based on coincident empty octahedral aluminium sites. On this basis, four different structural models characterized by different translation states have been proposed. They provide identical simulated images which describe perfectly the 
experimental HRTEM one. Among these four models, it has been found that the predicted structure presents a 2-fold screw symmetry axis including a glide component and leads to the least distorted $\mathrm{Al}$ - O bonds at the interface (Geipel et al. 1994, Lartigue-Korinek and Hagège 1998). On the basis of the coupled analysis of HRTEM image and O-K ELNES, the simulations using local density functional theory (LDFT) (Nufer et al. 2001) and lattice static calculations (Nishimura et al. 2003) confirm the lowest energy of this screw twin configuration which corresponds to the $\mathrm{S}(\mathrm{V})$ structure in reference (Marinopoulos and Elsässer 2000).

Taking into account an experimental sensitivity limit of 0.2 atom $/ \mathrm{nm}^{2}$, until now neither yttrium (Gülgün, Putlayev and Rühle 1999) nor other impurity (Ca, Si) (Gemming et al. 2003) segregation has been detected by STEM-EDXS analyses in such a $(01 \overline{1} 2)$ facet of the rhombohedral twin. Anyway, ab initio calculations of segregation revealed a propensity for yttrium to segregate on Al sites along this twin (Fabris and Elsässer 2003); this propensity varies with the different modelled structures (Elsässer and Marinopoulos 2001). The apparent contradiction between experiment and calculation is attributed by the authors to kinetic reasons as the rhombohedral twin GB structure is very close to the bulk structure.

In this paper, we present the analysis of a rhombohedral twin slightly deviated from the exact coincidence, thus containing intergranular defects. We will concentrate mainly on the Y-doped bicrystal in order to localise the dopant and to emphasize the atomic environment.

\section{II - Materials and experiments}

The alumina bicrystals are prepared by diffusion bonding and yttrium is laserdeposited before bonding (Vassiliev et al. 1997). The bonding temperature is $1700^{\circ} \mathrm{C}$ for $30 \mathrm{mn}$. The specimen is first thinned by the mechanical tripod technique, then made electron- 
transparent by a soft argon ion milling (DUO-MILL Gatan at $3 \mathrm{kV}$ with an $\mathrm{Ar}^{+} 0.5 \mathrm{~mA}$ current). A protective amorphous carbon layer is evaporated on both faces of the foil which is finally baked under high vacuum $\left(10^{-6}\right.$ Torr $)$ in order to prevent further contamination in the microscopes.

Deleted: secondary

\section{III - Results and discussion}

\section{III - 1 - GB structure and intergranular defects}

The structure of the studied Y-doped GB is considered by reference to the structure of the undoped bicrystal (Lartigue-Korinek and Hagège 1998). Both undoped and doped GBs present a similar tilt deviation from the rhombohedral twin orientation. This deviation is accommodated by a periodic array of two types of dislocations alternately distributed and quasi-parallel to the $\left[\begin{array}{lll}2 & \overline{1} & 1\end{array}\right]$ axis (fig. 1). Their Burgers vectors and associated step heights are determined by the King and Smith method on HRTEM images (King and Smith 1980). 
The two Burgers vectors of the coupled dislocations are $\vec{b}_{x}=\vec{b}_{1}+\vec{b}_{2}$ and $\vec{b}_{y}=\vec{b}_{3}$ (fig. 1a), knowing that $\vec{b}_{1}, \vec{b}_{2}, \vec{b}_{3}$ are translation vectors of the $\Sigma 7$ GB (Grimmer et al. 1990). The distance between $\vec{b}_{x}$ and $\vec{b}_{y}$ is $26 \mathrm{~nm}$ in agreement with the $0.8^{\circ}$ angular deviation from the coincidence orientation. The $\vec{b}_{2}$ and $\vec{b}_{3}$ Burgers vectors have a same component but with alternate sign along the $\left[\begin{array}{lll}2 & \overline{1} & \overline{1}\end{array}\right]$ axis such that $\vec{b}_{2}+\vec{b}_{3}$ is normal to the GB plane; this results in the long range stress field cancellation. The vectors $\vec{b}_{x}$ and $\vec{b}_{y}$ are associated with geometrically necessary GB steps (King and Smith 1980) whose heights are $1.75 \mathrm{~nm}$ and 1.39 $\mathrm{nm}$ respectively (i.e. $5 \mathrm{~d}$ and $4 \mathrm{~d}$ perpendicularly to the GB). The $\vec{b}_{1}$ Burgers vector is contained in the GB plane, so the $\vec{b}_{1}$ distribution accounts for the vicinality of the original bounded surfaces resulting in a non symmetrical GB plane.

The main modification of the GB due to the Y-doping (fig $1 \mathrm{~b}$ ) is the presence of numerous dislocations with several Burgers vectors that lead to a non-equilibrium configuration. In the Y-doped bicrystal, the dislocations distribution is non strictly periodic and some areas exhibit extrinsic dislocations whose Burgers vectors are various combinations of $\vec{b}_{1}, \vec{b}_{2}$ and $\vec{b}_{3}$ with different associated step heights. As a result, a long range stress field may be present.

In the next part, the Y segregation is investigated by EDXS along the GB with special focus on the specific dislocation array found in the Y-doped bicrystal.

\section{III - 2 - Yttrium segregation at intergranular dislocations by EDXS}

For the EDXS, EFTEM and EELS analyses and unlike for the CTEM observations of figure 1, the GB has to be oriented parallel to the electron beam. The normal of the foil being $[2 \overline{1} \overline{1} 0]_{1}$, the dislocations are also seen almost parallel to the beam. The overall elemental

Deleted: Consequently,

Deleted:

Formatted: Lowered by $5 \mathrm{pt}$ 
analysis and Y distribution in the GB is performed with the following procedure. First, spectra taken from rectangular scanned area (box size of $200 \mathrm{~nm}$ by $5 \mathrm{~nm}$ ) in the grains and along the grain boundary confirm the purity of the material: no other significant minor element is detected, except copper coming from the grid, argon coming from ionic thinning and carbon coming from accidental contamination. The $\mathrm{Y}-\mathrm{K}_{\alpha}$ peak is only detected when the box is centred on the grain boundary, given that no yttrium enrichment is observed in the adjacent alumina matrix. Secondly, in order to locate yttrium in the GB, a $1 \mathrm{~nm}$ probe is scanned with $1 \mathrm{~nm}$ steps along and across the GB around a defect. The segregation does not lie continuously in the GB: within an experimental detection limit of 0.2 at.\% Y, no Y is detected in the perfect twin parts, while strong $\mathrm{Y}$ enrichment is clearly evidenced only at isolated dislocations (fig. 2a). These two line scans - parallel and perpendicularly to the GB - allow to localize the distribution of the $\mathrm{Y}$ at the defect (fig. 2b). The measured dimensions of the $\mathrm{Y}$ segregated area, defined as the FWHM of the obtained intensity $\mathrm{Y}-\mathrm{K}_{\alpha}$ profiles adjusted for probe size and beam broadening, is about $4 \mathrm{~nm}$ along the GB and $2.5 \mathrm{~nm}$ perpendicularly to it. The apparent $4 \mathrm{~nm}$ length comes from the slight inclination of the dislocation about the projection axis. The relative elemental concentrations are extracted from the spectra using the Tecnai software (Tecnai Imaging and Analysis). Considering that the foil thickness is about or less than 50nm, no absorption correction is made. Given the used probe size in this experiment, the Y result is slightly underestimated due to the small tilt of the dislocation. A concentration value is thus estimated in the range of $0.7 \underline{0}$ at $\% \mathrm{Y}$ in the core of the defect. To be compared to the results found in the literature, this value has to be expressed in Y density per GB surface unity which assumes that $\mathrm{Y}$ lies in one intergranular plane. This will be experimentally confirmed in the $\S$ III-3. Then, a rough estimation of the areal Y density calculation (Gülgün, Putlayev and Rühle 1999) needs a convolution of the Y content result in the probed defect by the site density of $\mathrm{Al}$ in alumina and the width of the analyzed area (determined mainly by beam size). The final value is $1.70 \pm 1 \mathrm{at} / \mathrm{nm}^{2}$. By comparison with previous results from other authors, our value is closed to the mean value of Y segregation in general GBs in polycrystals which is found to be 1.75 atom $/ \mathrm{nm}^{2}$ whereas the largest value

\begin{tabular}{l} 
Formatted: Font: Not Bold \\
Formatted: Not Superscript/ \\
Subscript \\
\hline Formatted: Superscript
\end{tabular}


measured is $3.20 \mathrm{atom} / \mathrm{nm}^{2}$ (Gülgün, Putlayev and Rühle 1999). This last value corresponds to a coverage of $1 / 4$ monolayer.

\section{III - 3 - Yttrium location in the dislocation core by EFTEM}

It has to be noticed that, as mentioned above, the intergranular dislocation (fig. 3a) is linked to a large step and its associated line is slightly inclined with the $[2 \overline{1} \overline{1} 0]_{1}$ projection axis. As a consequence, any corresponding EELS signal is very low and very difficult to detect, even considering the very sharp Y-L 23 white lines. Moreover, the high energy loss of these Y-L $\mathrm{L}_{23}$ white lines $(2100 \mathrm{eV})$ implies very long recording times of the image series which can promote radiation damage and others shift problems. Consequently, the $\mathrm{Y}-\mathrm{N}_{23}$ edge which lies at much lower electron energy loss (37 eV) is used (Grigis and Shamm 1998). One series of energy filtered images is recorded made of fifteen filtered images 256 pixels $\mathrm{x}$ 256 pixels in size, every $2 \mathrm{eV}$ from $15 \mathrm{eV}$ to $43 \mathrm{eV}$ around $\mathrm{Y}-\mathrm{N}_{23}$ edge with a slit of $2 \mathrm{eV}$. The exposure time is 1s per image. Using Digital Micrograph_(Gatan Inc., USA), the images of the series are shown on Fig. 3a after alignment. Two line spectra are extracted from the EFTEM series: Fig $3 b$ corresponds to the line spectrum extracted across the perfect GB interface; in this case, each spectrum corresponds to a rectangular averaging area (box size : 30X3pixels i.e. $3.4 \mathrm{~nm} X 0.34 \mathrm{~nm}$ ) and the step between two spectra is $0.34 \mathrm{~nm}$. Fig. $3 \mathrm{c}$ shows the line spectrum extracted across the dislocation core; in this case, the sampling size and step are different: each spectrum corresponds to an averaging area, i.e. $(1.1 \mathrm{~nm} \mathrm{X} 0.11 \mathrm{~nm})$, the step between two spectra being 1pixel. Fig. $3 \mathrm{~d}$ exhibits two spectra: one spectrum is recorded in the matrix (full line) and the other one results from the sum of 3 spectra recorded at 3 different spots on the dislocation core projection (dashed line) to enhance the signal to noise ratio around $\mathrm{Y}-\mathrm{N}_{23}$ edge. On all the spectra (fig 3b, c, d), the large peak at $25 \mathrm{eV}$ corresponds to the bulk plasmon of $\alpha-\mathrm{Al}_{2} \mathrm{O}_{3}$, The $\mathrm{Y}-\mathrm{N}_{23}$ edge at $37 \mathrm{eV}$ is only detectable at the dislocation (fig. 3c). The intensity of the $\mathrm{Y}^{-\mathrm{N}_{23}}$ edge is insufficient to perform the most accurate localisation. $\underline{\text { A better } \mathrm{Y}-\mathrm{N}_{23}} \underline{\text { edge contribution is obtained by summing spectra recorded at }}$
Deleted: makes the signal of the defect undetectable even at $300 \mathrm{kV}$, within

Formatted: Font: Bold

Formatted: Font: Bold

Deleted: compatible with avoidance of Deleted: The

Deleted: range

Deleted:

Deleted: aligned and then rotated to have an horizontal GB as

Deleted: shows

Deleted: ing

Deleted: and is therefore seen all along the two line spectra on fig $3 \mathrm{~b}$ and $\mathrm{c}$

Deleted: weakness

Deleted: intensity does not allow

Deleted: a very 
different spots along the defect projection (fig $3 \mathrm{~d}$ ). The number of spectra affected by this feature on fig $3 \mathrm{c}$ is about 10 i.e. $1.1 \mathrm{~nm}$ corresponding to the dislocation core localisation The apparent length parallel to the GB comes from the dislocation tilting with respect to $[2 \overline{1} \overline{1} 0]$ axis.
- Additional information can be drawn from the broad shoulder whose onset is at $32 \mathrm{eV}$ and which is characteristic of the $\alpha-\mathrm{Al}_{2} \mathrm{O}_{3}$ low loss area. It has to be pointed out that this feature is slightly less intense where $\mathrm{Y}$ is present, i.e. in the dislocation core. This might be due to an irradiation effect which decreases the thickness by a very local abrasion under the beam. However, such a local effect is rather unlikely to occur under the parallel beam used in EFTEM experiment. On the other hand, could this $32 \mathrm{eV}$ shoulder be characteristic of the defect's structure? To answer this question, figure 4 shows some low loss spectra which have been previously recorded on the STEM VG microscope. These are reference spectra or "fingerprints" obtained from several alumina phases at the same thickness of 50nm: $\alpha-\mathrm{Al}_{2} \underline{\underline{O}}_{3}$ amorphous a- $\mathrm{Al}_{2} \underline{\mathrm{O}}_{3}$ and $\gamma-\mathrm{Al}_{2} \underline{\mathrm{O}}_{3} *{ }_{-}$The $32 \mathrm{eV}$ shoulder clearly appears only for the $\alpha-\mathrm{Al}_{2} \mathrm{O}_{3}$ phase but never for the other alumina phases such as the amorphous a- $\mathrm{Al}_{2} \mathrm{O}_{3}$ and $\gamma-\mathrm{Al}_{2} \mathrm{O}_{3}$ and more generally when there is less than six $\mathrm{O}$ anions around $\mathrm{Al}$ cation (Fig. 4). Therefore, the observation of a flattening of the $32 \mathrm{eV}$ shoulder on the defect introduces the hypothesis of a decrease of the $\mathrm{Al}$ coordination in the defect as compared to the adjacent grains and this will be carefully analysed on the Al- $\mathrm{L}_{23}$ edge in the next part.

\section{$\mathrm{III}-4-\mathrm{Al}^{3+}$ environment in the yttrium segregated dislocation core by ELNES.}

The atomic environment change of $\mathrm{Al}^{3+}$ due to $\mathrm{Y}$ segregation in the GB is investigated by EELS/ELNES. Few studies have been devoted to isolated dislocation by these techniques (Zhang et al. 2002). In our case, the ELNES analysis of Y and O in such sub-nanometric areas
Deleted: Nevertheless, $\mathrm{t}$

Deleted: and especially to the step

Deleted: A better $\mathrm{Y}_{-} \mathrm{N}_{23}$ edge

contribution is obtained by summing

spectra recorded at different spots along the defect projection (fig $3 \mathrm{~d}$ )

Deleted: An additional

Deleted: our previous EELS studies of alumina on the STEM-VG have shown

Deleted: that

Deleted: appears 
is very tricky because of the weakness of these signals. For different reasons, it is not possible to extract positive information from the ELNES of any of the three Y edges (Y-M, Y-N, Y-L). As for oxygen environment, we believe that reliable variations of O-K ELNES are very difficult to obtain with a good signal to noise ratio compatible with the absence of any radiation damage.

About ten intergranular dislocations have been analysed, For most of them, the extraction of the dislocation spectrum by processing data does not lead to any specific ELNES. In some other cases, a specific defect spectrum can be obtained which is not valid because of a suspicion of radiation damage. Finally, for a few dislocations, the $\mathrm{Al}-\mathrm{L}_{2} 2$ edge is not the same as the one in the bulk and in the twin part. We present and discuss this results.

On the HAADF (high angle annular dark field) image of the GB, the dislocations appear as white dots (fig. 5a) and the perfect twin parts have no contrast at all. These bright patches may be attributed to the Z-contrast intensity of $\mathrm{Y}$, consistent with the segregation of this element, although the $50 \mathrm{mrad}$ inner ADF angles used here cannot completely exclude a diffraction/strain contrast contribution. The apparent size of a dislocation is $4.5 \mathrm{~nm} \times 2.5 \mathrm{~nm}$, similarly to EDXS results.

In a first step, over the energy range containing the Al- $\mathrm{L}_{23}$ edge, an image-spectrum (Jeanguillaume and Colliex 1989) $\left(\mathrm{d}_{\text {probe }}=\sim 1 \mathrm{~nm}, 16\right.$ pixels x 16 pixels in size, 1 pixel $=0.5$ $\mathrm{nm}$, recording time $=50 \mathrm{~ms} / \mathrm{spectrum}, 0.2 \mathrm{eV} / \mathrm{channel}$ ) is recorded on the intergranular defect shown on figure $5 \mathrm{a}$. A chemical map of the Al atoms, extracted from this image-spectrum, does not detect any $\mathrm{Al}$ content variation between the grains and the twin part of the GB but clearly evidences an $\mathrm{Al}$ deficiency The area of this deficiency matches well the HAADF image of the defect (see figure 5a). Although this $\mathrm{Al}$ deficiency is not possible to quantify owing to diffraction contribution, this result is coherent with the hypothesis of the substitution of some $\mathrm{Al}^{3+}$ cations by $\mathrm{Y}^{3+}$ in the dislocation core
Deleted: with an even less than $1 \mathrm{~nm}$ probe

Deleted: and several results are obtained

Deleted: the repercussion on the A cations of the presence of $\mathrm{Y}$ in the structure is successfully evidenced on Deleted: which Formatted: Font: Not Bold Deleted: these

Deleted: $1 y$
Deleted: at the defect

Deleted: $4 \mathrm{a}$

Deleted: Again, $t$

Deleted: Owing to the diffraction contribution, only a rough idea of the $\mathrm{Al}$ reduction content in the defect can be deduced from this chemical map and it is valued at about less than 10 at. \% 
In a second step, Al bonding variations between bulk, perfect twin parts and intergranular defects are studied by monitoring the spatially resolved ELNES changes on the Al- $\mathrm{L}_{23}$ edge starting from the onset at $76 \mathrm{eV}$ and extending over the next $20 \mathrm{eV}$. This provides information about the local symmetry predominated by oxygen coordination around the central $\mathrm{Al}$ atom. The signal to noise ratios of the mentioned above spectra obtained with a recording time of $50 \mathrm{~ms}$ is good enough to estimate a chemical composition variation in an image-spectrum, but unfortunately not to analyse the ELNES. In this study, we are particularly careful about the specific radiation damage problems which are known to occur preferentially at GBs and defect areas (Bouchet and Colliex 2003). With this aim in mind, the recording time is increased up to $200 \mathrm{~ms}$ which is a good compromise given that a longer time of $500 \mathrm{~ms}$ is too much damaging. Furthermore, we have not used the image-spectrum tool which induces very strong cumulative charging effect in insulators (Bouchet and Colliex 2003). A less damaging line-spectrum ( 32 spectra, $t=200 \mathrm{~ms}$, step $=0.28 \mathrm{~nm}$ ) is recorded across the defect instead.

According to the intensity profile, the defect is "localized" on four pixels perpendicularly to the GB; this corresponds to $\sim 1.2 \mathrm{~nm}$ in size close to the EFTEM result. Two well-known data processing are used to extract the weak and specific defect spectrum: spatial difference (Bruley 1993) and multivariate statistical analysis (MSA) (Bonnet et al. 1999). The two methods give the same result which is the dislocation spectrum displayed on figure 5c. It is characterised by the ELNES features located at $77 \mathrm{eV}, 78.3 \mathrm{eV}, 79.5 \mathrm{eV}, 84 \mathrm{eV}$ and $99 \mathrm{eV}$. In the absence of any reliable knowledge and useful simulation of this complex Al- $\mathrm{L}_{23}$ edge, the only way to outline an interpretation of this spectrum is to compare it to Al$\mathrm{L}_{23}$ fingerprints. Such fingerprints have been established for several alumina phases and different $\mathrm{Al}$ coordinations at the same energy resolution (Bouchet and Colliex 2003) and for various Y-Al-O compounds (Gülgün, Ching and Rühle 1999). First of all, the Al-L $\mathrm{L}_{23}$ ELNES obtained for the defect are completely different from any of the Al-Y-O known compounds, The careful comparison between the dislocation spectrum (fig. 5c) and available $\mathrm{Al}-\mathrm{L}_{23}$ ELNES energy values reported on Table 1 from Bouchet and Colliex (2003) brings out the 
following important points: firstly, the defect structure is not amorphous but well ordered and secondly, $\mathrm{Al}$ cation is no more 6-fold coordinated by oxygen atoms $\left(\mathrm{Al} \mathrm{l}_{\rho \mathrm{ccta}}\right)$ : we can assert that it is neither purely 4 -fold coordinated $\left(\mathrm{Al}_{\text {tetra }}\right)$ nor 5-fold coordinated $\left(\mathrm{Al} \mathrm{l}_{\text {penta }}\right)$. The amorphous structure would be recognized mainly by the absence of any peak at about $84 \mathrm{eV}$ and by the presence of a peak at $80 \mathrm{eV}$ and not at $79.5 \mathrm{eV}$. Similarly, a pure 4-fold $\mathrm{Al}$ coordination would be characterised by a strong peak at $86 \mathrm{eV}$ and a sharp peak at $80 \mathrm{eV}$, which is not the case here. Thus, the dislocation spectrum is not a simple linear convolution of $\mathrm{Al}_{\text {tetra }}-\mathrm{L}_{23}$ and $\mathrm{Al}_{\text {octa- }}$ $\mathrm{L}_{23}$ spectra. On the other hand, the dislocation spectrum fits well with the fingerprints spectra of $\mathrm{Al}-\mathrm{L}_{23}$ in either $\gamma-\mathrm{Al}_{2} \mathrm{O}_{3}$ or $\theta-\mathrm{Al}_{2} \mathrm{O}_{3}$, thus indicating a combination of $\mathrm{Al}_{\text {tetra }}$ and $\mathrm{Al}_{\text {octa }}$ in a spinel type arrangement. The substitution of $\mathrm{Y}^{3+}$ cations to $\mathrm{Al}^{3+}$ ones in the defect induces a change in the atomic environment and part of the $\mathrm{Al}$ cations may become undercoordinated. At the moment, we are not able to distinguish between the fingerprints of the two spinels $\gamma_{-}-$ Deleted: structures of $\mathrm{Al}_{2} \mathrm{O}_{3}$ and $\theta-\mathrm{Al}_{2} \mathrm{O}_{3}$ which differ by the ratio $\mathrm{Al}_{\text {octa }} / \mathrm{Alt}_{\text {etra }}$. In the literature, several electronic structure calculations on special GB (Kenway 1994, Mo, Ching and French 1996) and EELS experiments on general GBs conclude also to a partial 4-fold Al coordination (Kaneko et al. 1998). Our result emphasizes the wealthy and complex information delivered by ELNES showing that the atom coordination is only one of the numerous parameters such as charge transfers, bond lengths, electronic configuration and so on, that are needed for their interpretation.

Furthermore, given that the segregated cation $\mathrm{Y}^{3+}$ is oversized (nearly twice the radius of $\mathrm{Al}^{3+}$ ), bondings between $\mathrm{Al}$ and $\mathrm{O}$ may be distorted as found by calculations (Elsässer and Marinopoulos 2001). Is this distortion detectable on the shape of the $\mathrm{Al}-\mathrm{L}_{23}$ edge? We have shown before (Bouchet and Colliex 2003) that the small bump preceding the threshold of the edge and located at $77 \mathrm{eV}$ is not related to 4-fold coordination as often mentioned in the literature (Bruley 1993) but undoubtedly due to an amorphisation or to some slight intrinsic disordering of the analysed area. Besides, this $77 \mathrm{eV}$ ELNES often appears in the case of damaged GB structures by a local and surreptitious radiation effect. Moreover, as far as radiation damage is concerned, an ELNES experiment is reliable only if one has checked that 
the bulk spectrum is strictly identical at the beginning and at the end of the line-spectrum, because of the above mentioned charge effects. All these considerations support the idea that no ELNES variations across the twin $\sum 7$ part of the GB is detected, indicating $\mathrm{Al}^{3+}$ in octahedral sites, as shown before by Gülgün, Putlayev and Rühle (1999). Nevertheless, such results obtained on a twin with an electron probe larger than the GB plane are to be treated with caution, especially because of the size of the used probe. Unfortunately, increasing the spatial resolution by oversampling is too much damaging in these GBs.

\section{IV - Summary and conclusions}

A combination of TEM techniques has shown that within the detection limits, $\mathrm{Y}$ is segregated in the dislocation cores of the rhombohedral twin $\sum 7$ in alumina slightly away from the exact coincidence and that no $\mathrm{Y}$ is detected along the perfect parts of the GB between the dislocations. This is in agreement with the fact that the twin GB is of low energy and with experiments already performed on intergranular defects in other system such as $\mathrm{Ni}$ doped molybdenum bicrystals (Pénisson and Vystavel 2000) where segregation has been found to occur only in dislocation cores or along high energy GBs. In the present study, the expansion of the perfect twin expected from simulations (Elsässer and Marinopoulos 2001) and due to $\mathrm{Y}$ segregation has not been reliably measured partly since no large perfect twin area can be found due to dislocation distribution. Besides, within the detection limit, neither $\mathrm{Y}$, nor any change in $\mathrm{Al}$ environment have been detected between dislocations. However, the localisation of $\mathrm{Y}$ is precisely enough determined to say that $\mathrm{Y}$ appears all along the dislocation line, From our experiments, Y segregation in the defect core/step is also accompanied by a change in the $\mathrm{Al}$ cation electronic environment and noticeably ELNES indicate that the core remains locally ordered even though a small bonding distortion is due to the strain induced by the large substituted $Y$ cations. Finally, an important point is that ELNES recorded on the dislocation core allow us to assert that $\mathrm{Al}^{3+}$ environment is similar to

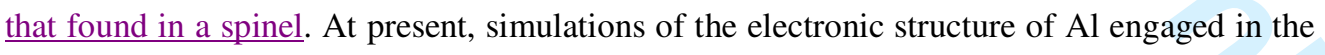

Deleted: i.e. along the large geometrically necessary steps associated with the dislocations

Deleted:

Deleted: These electronic changes and strains sustain the basic idea that segregation influences the dislocation mobility as illustrated by the non equilibrium dislocation distribution in the doped bicrystals

Deleted: of the spinel type 
alumina structures are not sufficiently refined and thus do not permit to fully interpret this result.

Nevertheless, these electronic changes and strains sustain the basic idea that segregation influences the dislocation mobility as illustrated by the non equilibrium dislocation distribution in the doped bicrystals.

\section{-}

\section{Acknowledgements}

E.A. Stepantsov and A.L. Vasiliev from the Institute of Crystallography of Moscow are gratefully acknowledged for the preparation of the bicrystals. We are pleased to thank $\mathrm{C}$. Colliex for careful and rewarding reading of the manuscript.

Bonnet N., Brun N. and Colliex C., (1999), Ultramic. 77, 97

Bouchet D., Dupau F. and Lartigue-Korinek S., (1993), Microsc. Microanal. Microstruct., 4,

Formatted: French (France) 561

Bouchet D. and Colliex C., (2003), Ultramic., 96, 139

Bruley J., (1993), Microsc. Microanal. Microstruct. 4, 23

Cawley J.D. and Halloran J.W., 1986, J. Am. Ceram. Soc., 69, C-195.

Chen F.R., Chu C.C., Wang J.Y. and Chang L., (1995), Philos. Mag. A, 72, 529

Deleted: Nevertheless, from o
it is believed that the elastic and

electronic consequences of Y segregation both contribute to dislocation mobility decrease.

Deleted: . From an experimental point of view, this work demonstrates the necessity of probing the grain boundary with a much better spatial resolution, in particular for the perfect twin part, in order to get information about both the electronic and structural configuration of the structural unit.

Deleted: II 
Cho J., Harmer M.P., Chan H., Rickman J. M. and Thompson A.M., 1997, J. Am. Ceram.

Soc., 80, 1013

Elsässer C. and Marinopoulos A.G., 2001, Acta mater., 49, 2951.

Fabris S. and Elsässer C., 2003, Acta mater., 51, 71.

Geipel T., Lagerlöff K.P.D., Pirouz P. and Heuer A.H., 1994, Acta mater., 42, 1367.

Gemming T., Nufer S., Kurtz W. and Rühle M., 2003, J. Am. Ceram. Soc., 86, 581.

Formatted: German (Germany)

Grigis Ch., Schamm S., 1998, Ultramic., 74, 159.

Grimmer H., Bonnet R., Lartigue S. and Priester L., 1990, Philos. Mag., A, 61, 494.

Gruffel P. and Carry C., 1993, J. Eur. Ceram. Soc., 11, 189.

Gülgün M.A., Putlayev V. and Rühle M., 1999, J. Am. Ceram. Soc., 82,1849.

Gülgün M.A., Ching W.Y. and Rühle M., 1999, Materials Sciences Forum, Vols 294-296, 289.

Jeanguillaume C. and Colliex C., Ultramic., 1989, 28, 252.

Formatted: French (France)

Kaneko K., Gemming T, Tanaka I. and Müllejans H., 1998, Philos. Mag., A 77, 1255.

Formatted: German (Germany)

Kenway P.R., 1994, J. Am. Ceram. Soc., 77, 349.

King A.H. and Smith D.A., 1980, Acta Cryst., A 36 (3), 335.

Formatted: Font: Bold

Lartigue-Korinek S. and Hagège S., 1998 in "Intergranular and Interphase Boundaries in

Materials", Trans Tech Publishing Ldt., Prague, Czech Republic, p. 281.

Lartigue-Korinek S., Carry C. and Priester L., 2002, J. Europ. Ceram. Soc., 22, 1525.

Loudjani M.K. and Cortes R., 1994, J. Eur. Ceram. Soc., 77, 349

Formatted: Font: Bold

Marinopoulos A.G. and Elsässer C., 2000, Acta mater., 48, 4375.

Mo S.D., Ching W.Y. and French R.H., 1996, J. Am. Ceram. Soc., 79, 627.

Nishimura H., Matsunaga K., Saito T., Yamamoto T. and Ikuhara Y., 2003, J. Am. Ceram.

Soc., 86, 574 .

Nufer S., Marinopoulos A.G., Gemming T., Elsässer C., Kurtz W., Kostlmeier S. and Rühle M., 2001, Phys. Rev. Lett., 86, 5066.

Penisson J.M. and Vystavel T., 2000, Acta Mater., 48, 3303.

Vasiliev A.L., Stepantsov E.A., Ivanov Z.G., Olson E., Verbist K. and Van Tendeloo G., 1997, Interface Science, 5, 223. 
Wang C.M., Cargill G.S., Chan H.M. and Harmer M.P., 2000, Acta mater., 48, 2579.

Zhang Z., Sigle W. and Rühle M., 2002, Phys. Rev. B 66, 1. 


\section{Figure caption}

Figure 1 : CTEM images of the rhombohedral twin GB in alumina:

(a) the undoped bicrystal contains a periodical array of parallel coupled dislocations

(b) Only some parts of the Y-doped bicrystal (white curly brackets) contain arrays similar to $\underline{\text { the one in (a). The other parts of the GB contain extrinsic dislocations with different Burgers }}$ vectors (one of them is white arrowed).

Figure 2: EDXS analysis:

(a) spectra showing the presence of $\mathrm{Y}$ segregation in the intergranular defect and not in the rhombohedral twin parts of the GB.

Y profiles across (b) and along (c) the GB allow the measurement of the Y extent in the defect $(4 \mathrm{~nm} \times 2.5 \mathrm{~nm})$

Fig 3 : EFTEM experiments

(a) Image extracted from a filtered series recorded at an energy loss of $25 \mathrm{eV}$ with a $2 \mathrm{eV}$ slit. It has to be pointed out the excellent contrast preservation of the HREM image even in these conditions.

(b) and c) show line spectra between $15 \mathrm{eV}$ and $43 \mathrm{eV}$ extracted from the EFTEM series. (b) is across the perfect GB interface and (c) is across the dislocation; about 10 spectra exhibit the $\mathrm{Y}-\mathrm{N}_{23}$ edge at $37 \mathrm{eV}$. The « width » of the dislocation core corresponds to $1 \mathrm{~nm}$ which is in fact of the order of the step height associated with the dislocation core (see a)).

(d) The comparison between a spectrum recorded in the matrix (full line) and one resulting from the sum of 3 spectra recorded at 3 different spots on the dislocation core projection (dotted line) enhances the signal to noise ratio around $\mathrm{Y}-\mathrm{N}_{23}$ edge.

Fig. 4: Low loss reference spectra of several alumina phases recorded at the same thickness $(\mathrm{t}$ $=50 \mathrm{~nm}$ ) on a STEM-VG. Only one spectrum is shown forthe a- $\mathrm{Al}_{2} \mathrm{O}_{3}$ and $\gamma-\mathrm{Al}_{2} \mathrm{O}_{3}$ spectra which are similar.

\begin{tabular}{l}
\hline Deleted: of alumina \\
\hline Deleted: . \\
\hline Deleted: $/ \lambda$ \\
\hline Deleted: $0.5^{*}$ \\
\hline Deleted: given that \\
\hline
\end{tabular}


Figure 5: EELS experiments

a) The main high angle annular dark field image shows the rhombohedral twin and the defects separated by $26 \mathrm{~nm}$ (see fig 1 ). The black square defines the area of the image-spectrum around a defect $(16 \times 16$ pix, 1 pix $=0.5 \mathrm{~nm}, 50 \mathrm{~ms} /$ spectrum $)$. The $\mathrm{Al}$ map indicates a decrease of this element in the $\mathrm{Y}$ rich defect.

b) Bulk and dislocation $\mathrm{Al}-\mathrm{L}_{23}$ absorption edges extracted from a line-spectrum across the intergranular defect (32 spectra, $\mathrm{t}=200 \mathrm{~ms}$, step $=0.28 \mathrm{~nm}$ )

(c) Processing data by both MSA and spatial difference allow to extract the defect spectrum (the combination of the energy values of the ELNES indicates a spinel type structure) and the absence of any radiation damage during the recording of the line-spectrum (i. e. the difference spectrum between the last and the first spectrum is flat). 


\begin{tabular}{|c|c|c|c|c|c|c|c|c|c|c|c|}
\hline \multirow[t]{2}{*}{ Phases } & \multirow[t]{2}{*}{ Al-coordination } & \multicolumn{10}{|c|}{ Energy values $(\mathrm{eV})$ of the ELNES features $( \pm 0.3 \mathrm{eV})$} \\
\hline & & $\mathbf{a}$ & b & c & d & e & $\mathbf{f}$ & $\mathbf{g}$ & $\mathbf{h}$ & $\mathbf{i}$ & $\mathbf{j}$ \\
\hline $\mathrm{AlPO}_{4}$ & 4 & & & 78 & & & 80 & & & & 86 \\
\hline $\mathrm{Al}_{2} \mathrm{Ge}_{2} \mathrm{O}_{7}$ & 5 & & 77.5 & & & 79.5 & & & & & 86 \\
\hline$\alpha-\mathrm{Al}_{2} \mathrm{O}_{3}$ & 6 & & & & 79 & & 80 & 83 & & 85 & \\
\hline am $-\mathrm{Al}_{2} \mathrm{O}_{3}$ & mixed & 77 & & & & & 80 & & & & \\
\hline$\gamma-\mathrm{Al}_{2} \mathrm{O}_{3}$ & $(0.3) 4+(0.7) 6$ & & & 78 & & 79.5 & & & 84 & & \\
\hline$\theta-\mathrm{Al}_{2} \mathrm{O}_{3}$ & $(0.5) 4+(0.5) 6$ & & & 78 & & 79.5 & & & 84 & & \\
\hline Dislocation & 23 & 77 & & 78 & & 79.5 & & & 84 & & \\
\hline
\end{tabular}

Table I: Energy values over the first $11 \mathrm{eV}$ above threshold of the ELNES features of Al- $\mathrm{L}_{23}$ fingerprints for six different atomic environment of Al atoms (Bouchet and Colliex 2003). The results of this study about the ELNES of the intergranular defect is added showing clearly the similarity with the two spinel aluminas. 


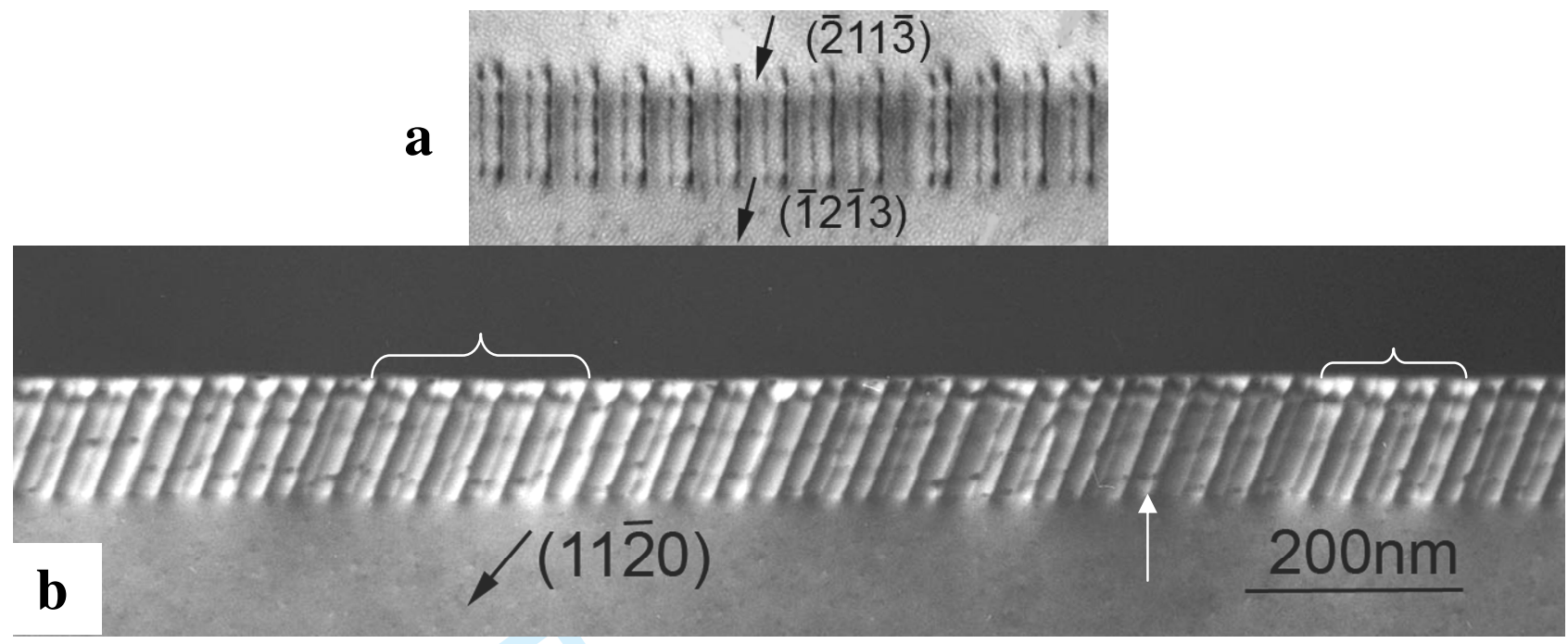

Fig 1 
2 D. Bouchet et al.

3 


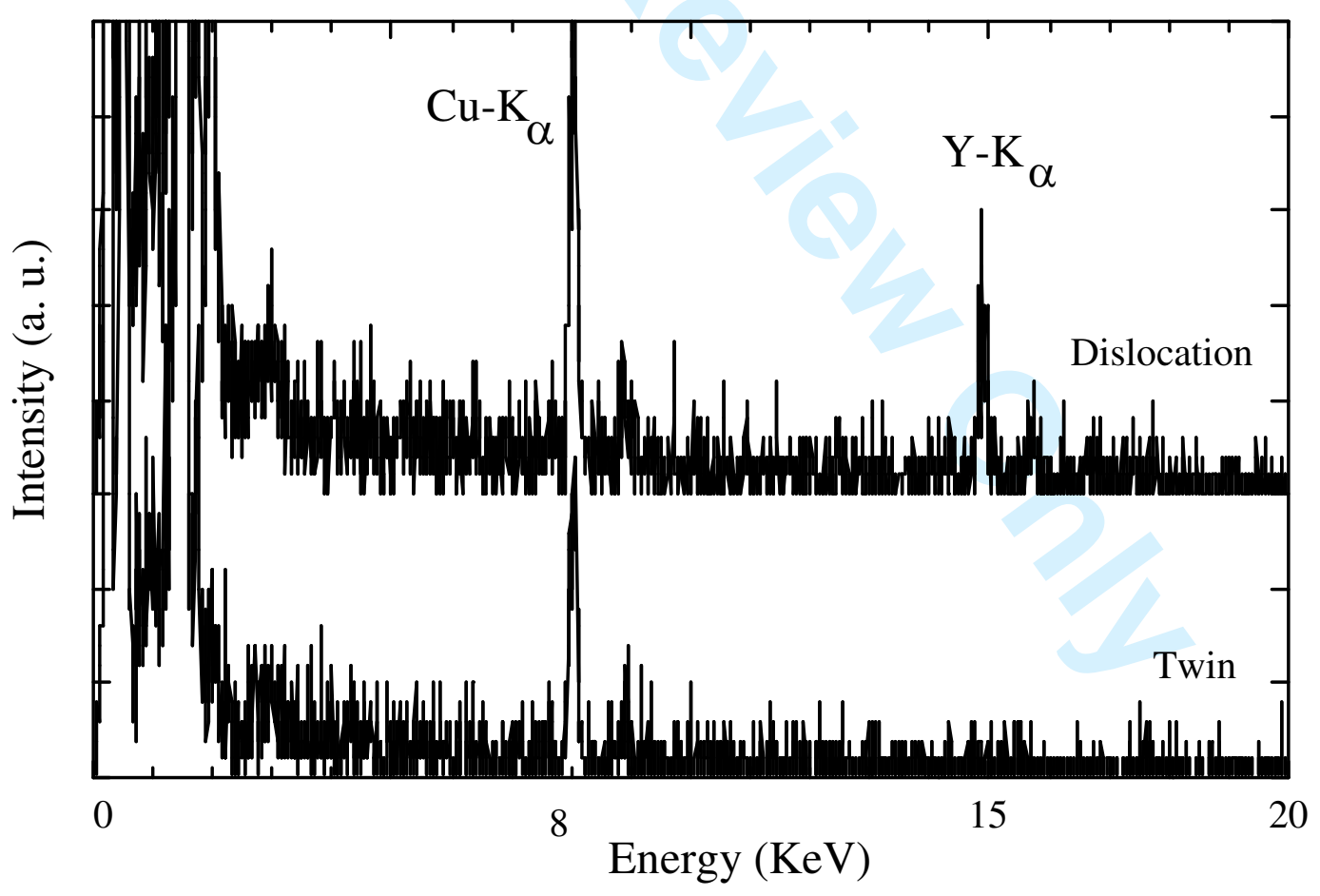

Fig. 2a

D. Bouchet et al. 

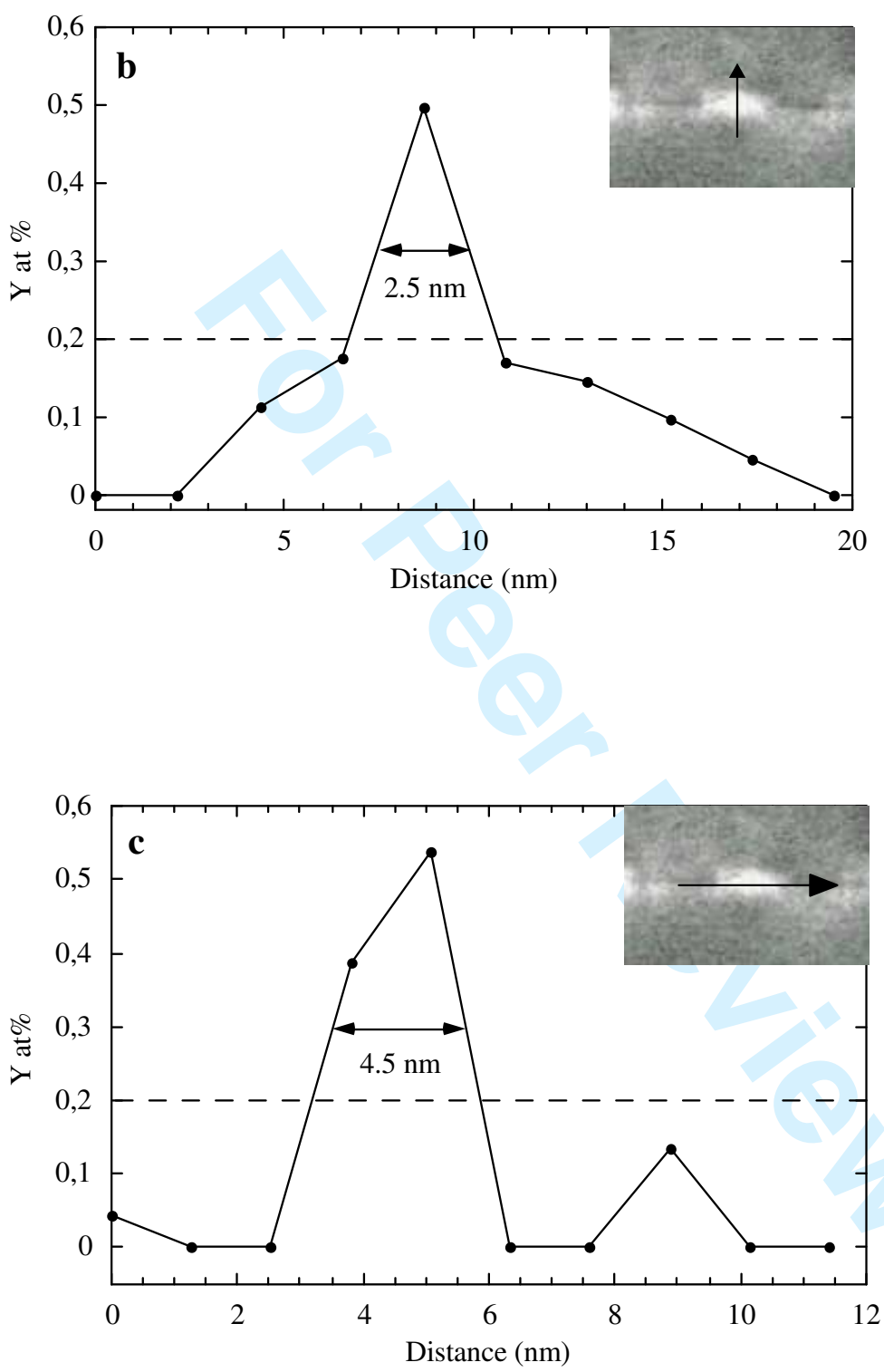

Fig. 2 bc

D. Bouchet et al. 
a
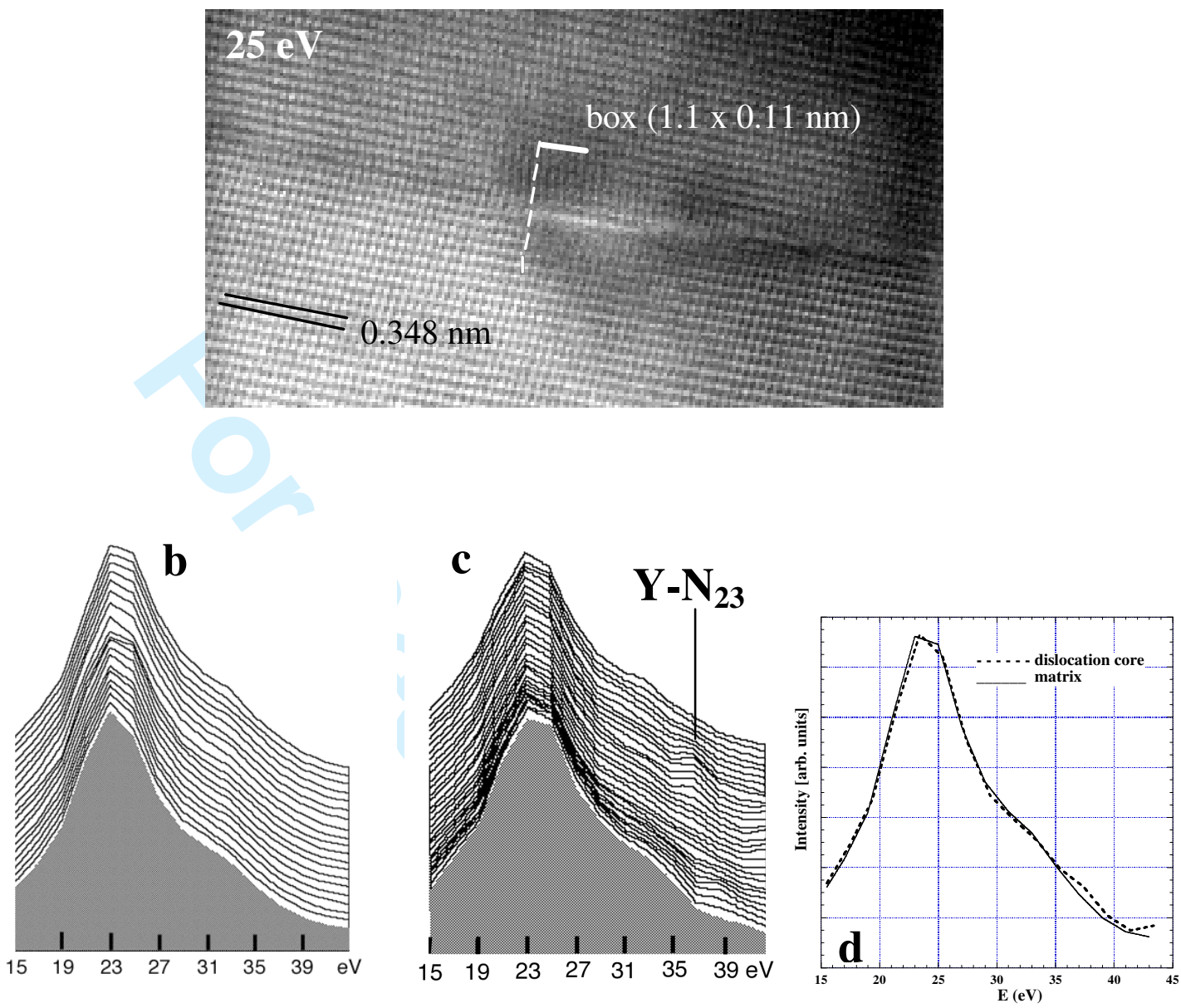

Fig 3 :

D. Bouchet et al. 


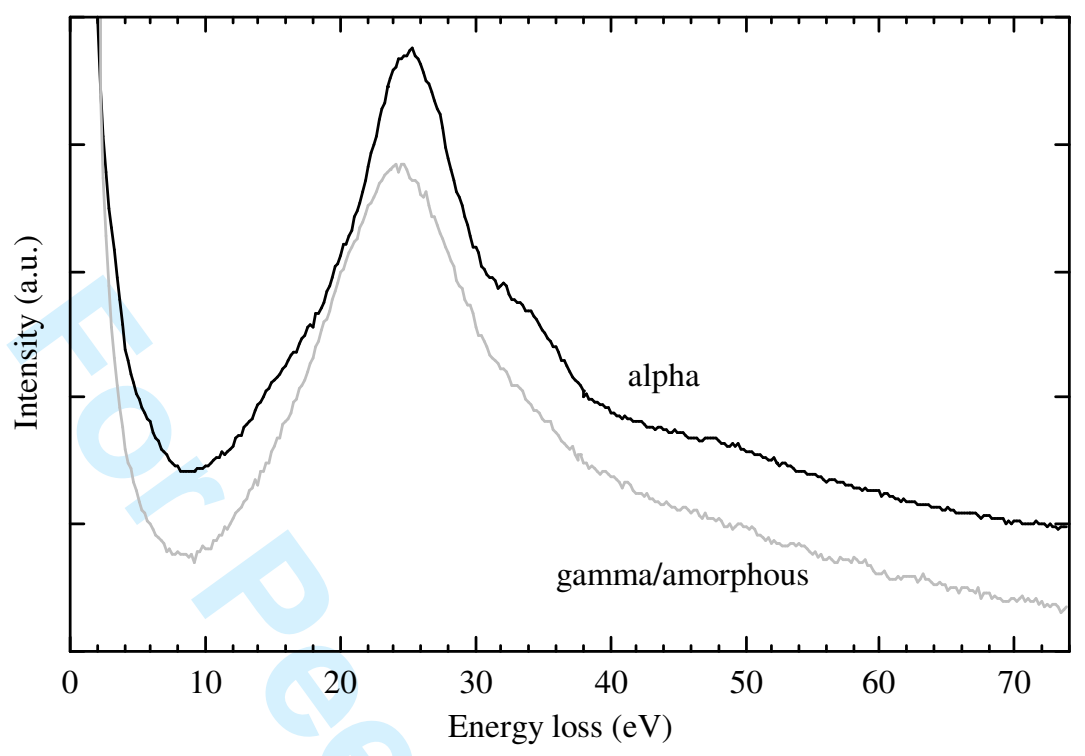

Fig 4.

D. Bouchet et al. 

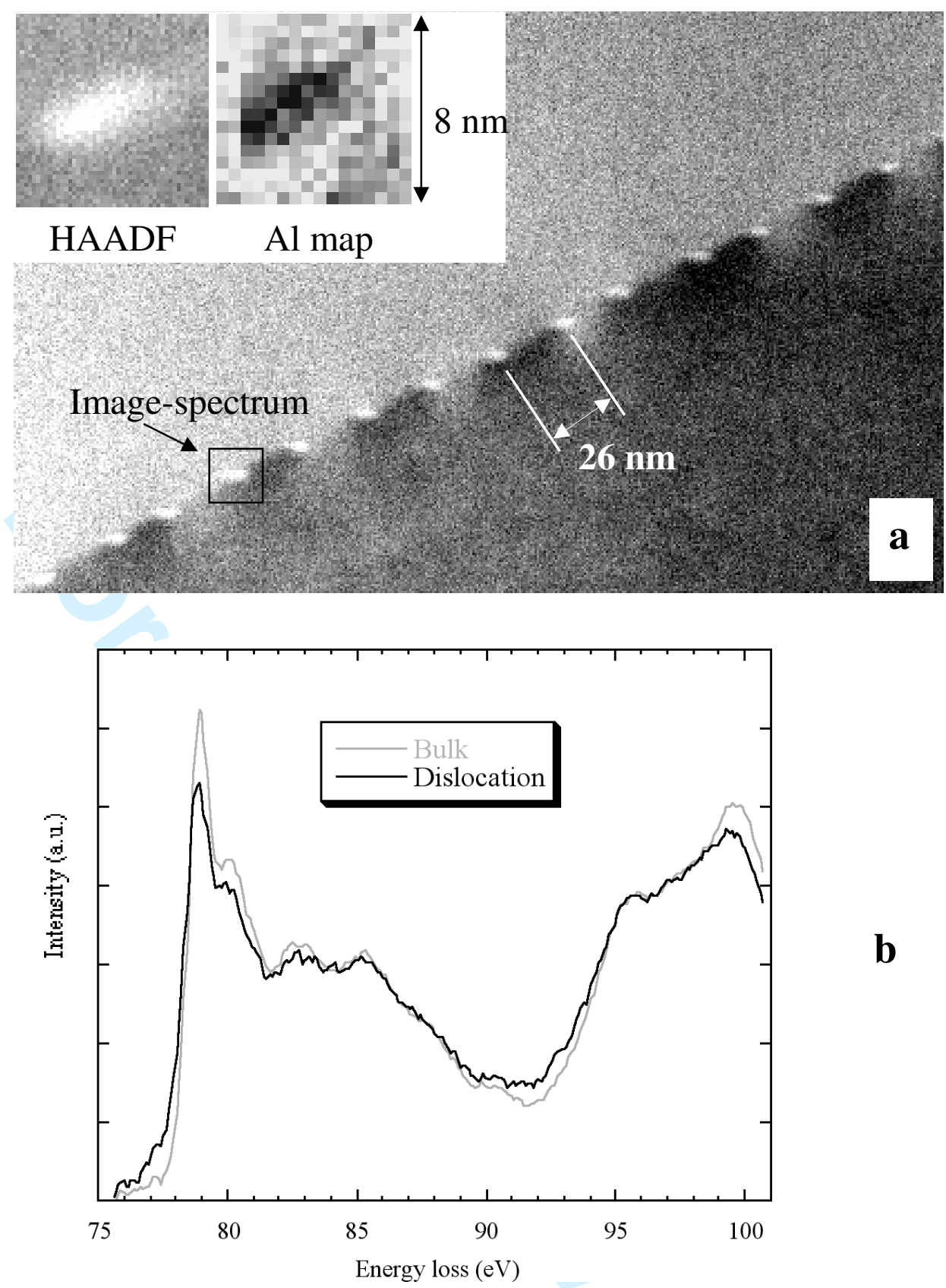

b

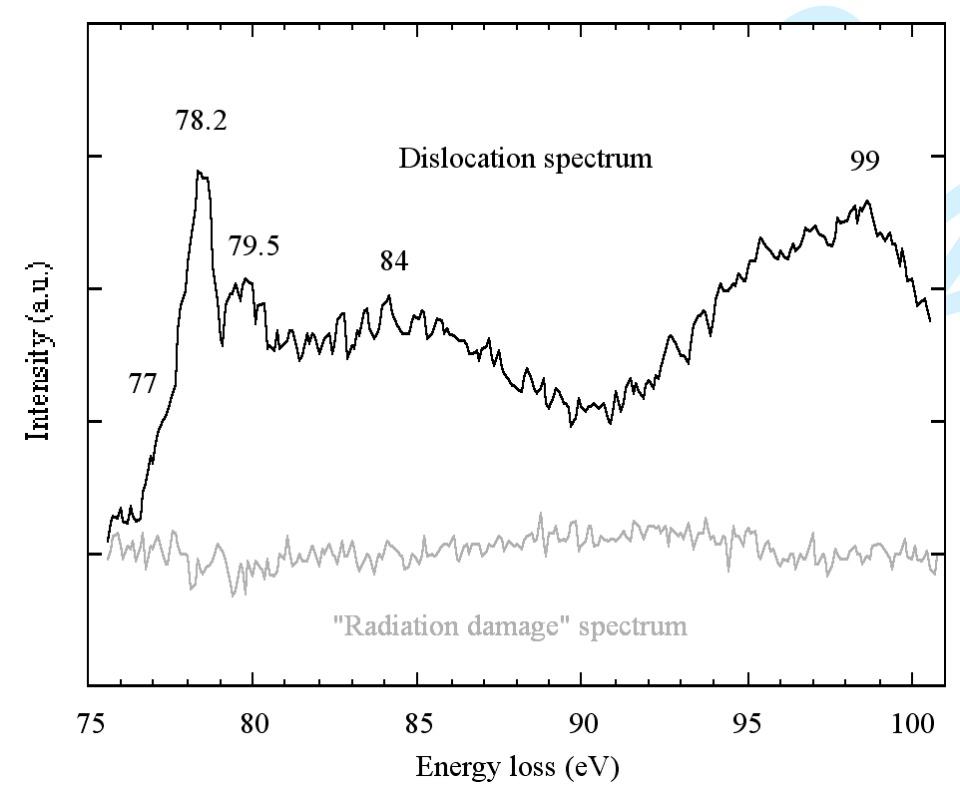

Fig 5: D. Bouchet et al. 